\title{
ON THE STATUS OF TERMINAL DEVOICING AS AN INTERLANGUAGE PROCESS AMONG BRAZILIAN LEARNERS OF ENGLISH
}

\author{
Márcia Cristina Zimmer \\ Ubiratã Kickhöfel Alves \\ Universidade Católica de Pelotas
}

\section{Abstract}

This paper investigates the status of Terminal Devoicing in the light of connectionism, by revisiting this process in a more dynamic framework. It focuses on the acquisition of two acoustic cues that distinguish final voiced from voiceless stops in English: (1) percentage of voicing in the stop closure; (2) length of the vowel that precedes the obstruent. Data obtained from Brazilian students of English were compared to those collected from American speakers, in order to check whether the learners' productions differed significantly from native speech. Results showed that neither voicing in the closure nor vowel length were totally neutralized, which indicates that learners are starting to distinguish final voiceless and voiced stops.

Keywords: Terminal Devoicing, connectionism, interlanguage phonology. 


\section{Introduction}

Connectionism assigns a great deal of relevance to previous linguistic knowledge and to the experience with such knowledge, which is entrenched in the learner's cognitive system, in the construction of new linguistic representations (Seidenberg \& Zevin, 2006). The process of Terminal Devoicing is investigated here with the aim of highlighting the role of experience with L1 knowledge in dealing with the L2 ${ }^{1}$ phonetic-phonological patterns (Zimmer, 2004) and the process of transfer (MacWhinney, 2002, 2007), which is also involved in learning a Second Language.

Departing from distinct findings from different studies investigating Terminal Devoicing (TD) among Brazilian learners of English, this investigation discusses the status of this process as an interphonology process, presenting a new investigation, whose method was designed to answer the following questions and hypotheses:

1) Is TD an interpholonogy process charaterized by total neutralization of voicing? In case it is not, do Brazilian learners present a significantly shorter percentage of voicing duration in the closure than native American speakers of English in voiced obstruents? Our hypothesis is that Brazilian learners produce a significantly shorter percentage of voicing duration in the closure of voiced obstruents than American speakers of English do.

2) Is vowel duration a significant parameter distinguishing voiced from voiceless obstruents in the English spoken by Brazilian learners? The hypothesis is that vowel duration is a significant parameter distinguishing voiced from voiceless obstruents in the English spoken by Brazilian learners.

The answers to these questions guide the discussion about the status of Terminal Devoicing as an interlanguage process in a classic view of interphonology, arguing for a dynamic view of interlanguage phonology. 


\section{Connectionism, SLA, L1-L2 Transfer and Terminal Devoicing}

In this section, the main features of cognition operating in SLA are approached within a connectionist perspective, the role of transfer in interphonology is briefly presented, and Terminal Devoicing is described in both a classical and in a more dynamic perspective. For that purpose, this section is divided into three parts, which deal with (1) connectionism and SLA, (2) TD as an interlanguage process, and (3) TD in the languages of the world: evidence from acoustic phonetics.

\subsection{Connectionism and SLA}

The connectionist approach studies language acquisition as a constructive process driven by data and based on universals of cognitive structure (MacWhinney, 2001). Connectionist research investigates the nature of cognitive mechanisms underlying the learning of phonological, semantic and syntactic processes. Input takes on a fresh role in connectionism: it is seen as being rich enough to drive learning based on its probabilistic information. This assumption can be summed up in four main claims: (a) the linguistic environment is rich in distributional regularities which guide language learning; (b) language acquisition requires the exploration of probabilistic constraints contained in the various types of linguistic and nonlinguistic information; (c) it is hard to define a clear borderline between linguistic and nonlinguistic knowledge, since the success of learning depends on both the structured input and the learner's previous knowledge; (d) the distributional information can provide implicit evidence for language acquisition (Rhode \& Plaut, 2003; Seidenberg \& McDonald, 1999).

This approach clashes with the traditional notion of phonological acquisition in a symbolic paradigm. According to Zimmer, Silveira \& Alves (in press), an input representation conceived as a deep structure far apart from the output form effectively produced cannot be accepted, for an input form shall not be distinct from the oral stimulus to which the learner is exposed. In other words, the ambient language is not only 
the departure point from which the learners will extract the regularities of the linguistic system, but it is also the target end-point of language acquisition itself.

In the case of SLA, the classic approach ${ }^{2}$ to interphonology is based on a concept of interlanguage which relies on the notion of markedness. Within the classic symbolic tradition, Eckman (1996, p. 198) defines markedness as follows: "A phenomenon $\mathrm{A}$ in some language is more marked than $B$ if the presence of $A$ in a language implies the presence of $B$; but the presence of $B$ does not imply the presence of A." Silveira (2004) gives a good example of the traditional concept of markedness by explaining that a language like English, which has three-element consonantal sequences in word-final position, is more marked, in terms of syllable structure, than Brazilian Portuguese, which allows only sequences of two consonants in the same position.

This classic view of markedness is disregarded by connectionism. In fact, markedness is such a broad and ill-defined concept that Haspelmath (2006) describes twelve different senses for the term, grouping them into four larger classes: markedness as complexity, as difficulty, as abnormality, and as a multidimensional correlation. Information contained in the structured input, such as how articulatorily complex it is, how often it is produced in some contexts and how absent it is can be gradually perceived and tallied by the learner (Ellis, 2005). In fact, we agree with Haspelmath (2006) that 'the term 'markedness' is superfluous, because some of the concepts that it denotes are not helpful, and others are better expressed by more straightforward, less ambiguous terms" (p. 25).

The discussion above suggests that this construct does not help to clarify the issue of interlanguage processes in second language acquisition, as we shall see later, in section 2.2; rather, it causes a great deal of confusion and ambiguity. Therefore, we can replace the concept of markedness with the role of the learner's linguistic experience, associating it to the human capability of tallying important and salient input characteristics, guided by the frequency and consistency of certain segments, gestures or gestural sequences. This experience is the product 
of the learners' general cognitive capacity to make associations departing from the data available in the L1 and the L2 input.

The connectionist perspective on second language acquisition focuses on linguistic experience and transfer as the key factors for learning and memory consolidation. According to MacWhinney (2007), the L1 and the L2 rely on the same neuronal architecture. Therefore, linguistic transfer can be explained as transfer of information among neural networks which are guided, along the time-consuming course of language learning, by factors related to L1 and L2 input quantity and quality, as well as the role of L1 knowledge in L2 learning. Thus, the notion of transfer is very important for enhancing the L1-L2 phoneticphonological interaction, which is a very important concept in a dynamic approach to interlanguage processes such as TD.

\subsection{Terminal Devoicing as an interlanguage process}

The L2 phonetic-phonological processing is seen here as biased by the entrenched experience the learner has gleaned from his/her use of the L1 and the L2, as well as from the metalinguistic knowledge the learner has built about the two languages in his cognitive system (MacWhinney, 2001; 2007; Seidenberg \& Zevin, 2006).

The ability to generalize is fundamental for learning. Deviant L2 productions usually derive from the learner's experience with the L1 and L2 inputs, which in turn give rise to the generalization of knowledge from the L1 into the L2 (L1-L2 transfer), and also to overgeneralizations of L2 input. The first type of generalization is interlanguage transfer, whereas the second type of generalization is intralanguage transfer. As to the first type of overgeneralization, interlanguage transfer, it can be further devided in two kinds of generalization of L1-L2 knowledge, from which two interactive kinds of L1-L2 transfer emerge: 1) phoneticphonological transfer, which occurs during L2 oral production;2) graphophonic-phonological ${ }^{3}$ transfer, which happens during oral reading in the L2, but can also occur during speech production itself, since it is really hard to separate one from the other, given the high interactivity of the human cognitive processing system (Zimmer \& Alves, 2006; 
Zimmer, Silveira \& Alves, in press). This paper focuses on the incidence of Terminal Devoicing among Brazilian learners of English as deriving mainly ${ }^{4}$ from the first kind of transfer.

In a classic approach to interphonology, TD consists of the loss of the voicing feature in certain final obstruents (Major, 1987). Moreover, it can occur both in the L1 and in the L2.

$$
\text { [-son] } \rightarrow[- \text { voi }] / \ldots \#
$$

According to Major (1987), as Brazilian learners of English tend to devoice final obstruents in English words followed by a pause, there would be a rule in their interlanguage which does not exist in their L1 nor in their L2, since in English final voiced obstruents do not lose their voiced feature. In Major's (1987) experiment, the participants read a word list, a sentence list and a text. In the oral reading data, Major found a rate of use of TD of $13,9 \%$ in the group of 6 advanced students, and $27 \%$ of incidence among 6 beginners.

In his study, Major relied on phonetic transcription based on the auditory capacity of the transcribers regarding the data. This may have hindered a more precise measurement of the collected data. Yavas (1997) investigated the effects of place of articulation of the final voiced stop and the height of the preceding vowel in the devoicing of English voiced stops in interlanguage phonological production. The author investigated the production of English words by speakers of Mandarin Chinese, Japanese and Portuguese, as these three languages do not allow stop codas. By analyzing his data acoustically, the author measured the duration of voicing in the closure, which is one of the two cues addressed in the present study. Yavas (op. cit), besides pointing out that the rate of devoicing in non-native English speech was much greater than that produced by native speakers, also shows that the effect of place of articulation is greater when the preceding vowel is high. Thus, he shows that changing the vowel height has as significant effect on alveolars and velars, but not on bilabials. 
Zimmer and Alves (2007) designed another study in which the proportion of voicing in the obstruent closure was measured using the software Praat - Version 4.4.22 (Boersma \& Weenink, 2006). The authors investigated the production of 8 female students of English at four different proficiency levels (beginner, intermediate, upperintermediate and advanced) in Southern Brazil and concluded that final $/ \mathrm{b} /, / \mathrm{d} /$ and $/ \mathrm{g} /$ were partially (not totally) voiced by the informants. Partial voicing distinguished $/ \mathrm{b} /, / \mathrm{d} /$ and $/ \mathrm{g} /$ from final $/ \mathrm{p} /, / \mathrm{t} /$ and $/ \mathrm{k} /$, which were produced with no voicing in the closure at all. Moreover, they did not find significant effects of level of proficiency over the degree of devoicing in the participants' production. The results discussed in Zimmer and Alves (2007) conclude that TD is a dynamic process. Hence, it should not be regarded as the total loss of voicing in the obstruent closure; rather, it ought to be understood as a series of articulatory phenomena which cannot be accounted for without taking intrinsic time into consideration. However, the authors remarked that additional acoustic cues, such as the length of the vowel preceding the final obstruent, should be considered in studies to follow. In the next section, we discuss the status of these acoustic cues in different languages: the proportion of voicing in the closure of final obstruents and the length of the preceding vowel.

2.3 TD in the world's languages: evidence from Acoustic Phonetics

Terminal Devoicing is incomplete in Dutch, as the distinction in the length of the release burst is preserved in [t] and [d] (Ernestus \& Baayen, 2006). The same can be said about German, in which the total neutralization of some acoustic cues (such as vowel length and closure voicing) occurs, but not of others, as the stop duration is not affected (Piroth \& Janker, 2004).

In English, plosives that undergo final devoicing do not share the same acoustic properties as voiceless segments (Flege et al., 1987). Native speakers of English, thus, are able to distinguish final [p] and $[b]$ or $[t]$ and [d]. However, partial phonetic devoicing also occurs in 
English. For instance, native productions of devoiced [z] were organized by Smith (1997) in three categories: devoiced [z] (0 to 25\%); partially devoiced [z] (25 to 90\%); voiced [z] (90 to 100\%). In addition, differences concerning the length of the fricative itself were also pointed out: the duration of $[z]$ was significantly shorter than the voiceless counterpart [s]. Differences in the length of the preceding vowel were also found, the vowels followed by [z] being significantly longer than those preceding [s].

Voicing in the closure (or its absence) seems to be an important cue in the contrast between English [p] and [b]. The native speakers of English who participated in the study by Flege et al. (1987) maintained closure voicing from 60 to $120 \mathrm{~ms}$ in word-final [b], in total closure intervals which ranged from 100 to 140 miliseconds. Devoicing was, therefore, partial. The duration of voicing in the closure is influenced by several factors, among which the effects of place of articulation should be considered. Voicing in the closure tends to decrease as the tongue moves backwards. This is a consequence of the fact that, the further back the place of articulation, the easier it is for the intraoral (also called supraglottal) pressure behind the oral obstruction to grow. For voicing not to cease, supraglottal pressure must be maintained below subglottal air pressure, as this is a necessary condition for airflow to go up through the glottis. According to Kingston (manuscript), in order to maintain supraglottal above subglottal pressure, speakers tend to "both actively expand the oral cavity and allow it to expand passively by relaxing the muscles lining its walls when pronouncing voiced obstruents" (Kingston, op. cit.). In velar stops, both active and passive expansions tend to be more difficult. The oral cavity is not actively expanded as much in velar as in bilabial or alveolar stops. Besides, velar stops, when compared to bilabial and alveolar ones, have the smallest area of compliant tissue behind the closure, and this fact accounts for less passive expansion.

With regard to vowel length, as we consider a minimal pair such as feed - feet in English, it is clear that the vowel in the first member of the pair is longer than the vowel in the second word. In English, 
whenever a vowel is followed by a voiceless consonant, the length of the vowel tends to be shorter. This happens because consonants such as $/ \mathrm{p} /, / \mathrm{t} /$ and $/ \mathrm{k} /$ tend to be produced with more force of articulation, and when they are produced in syllable-final position, their preceding vowel has its length affected, so that the voiceless consonant can fit in the same syllable structure. Consonants such as [b], [d] and [g], in turn, are not produced with great force, which allows the preceding vowel to be produced with no reduction in length. Vowel length is one of the greatest perceptual cues employed by native speakers of English. Many authors (Ladefoged, 1993; Celce-Murcia et al., 1996, among others) have stated that the vowel/consonant durational ratio, rather than the vibration of the vocal folds in the closure, represents the main cue used by native speakers of English to distinguish final $/ \mathrm{p} /-/ \mathrm{b} /, \mathrm{t} / \mathrm{-} / \mathrm{d} /$ and $/ \mathrm{k} /-\mathrm{g} /$.

These facts considered, we investigate whether Brazilian learners use the vowel/consonant ratio cue in the production of English words. We will also check whether (and to what extent) closure devoicing occurs in English / Brazilian Portuguese interlanguage phonology. This will be done in the sections that follow.

\section{Method}

Participants in the Brazilian group were 8 female learners between the ages of 19 and 26, students at the Universidade Católica de PelotasRS. They were native speakers of Brazilian Portuguese, and had not been exposed to any other language apart from English. So as to determine the learners' proficiency level, they all took the TOEIC (Test of English for International Communication) proficiency test, which indicated that all learners belonged to either the upper-intermediate or the advanced level. The North-American group consisted of 3 female native speakers of North-American English, all of them residents in Amherst, Massachusetts (USA), at the time of recording. The three speakers were born in the Northeast of the United States, and had not learned any other language but English before adolescence. Their ages 
ranged from 25 to 32 . The participants from both groups took a wordreading test whose lexical items had been selected in order to allow the emergence of the process of Terminal Devoicing. The instrument consisted of the following target words: 1) six lexical items ending in voiced plosives: bad, pad, bob, cab, rag, bag; 2) six correlates to the words in (1), ending in voiceless plosives and fricatives, so that the production of words ending in voiced and voiceless segments could be compared: bat, pat, bop, cap, rack, back.

The twelve words listed above were presented to students in carrier sentences (Say___ ), which were repeated five times for each one of the words. These sentences were presented in a random fashion, along with 8 distractor items, which were also repeated five times each. Thus, the version of the instrument presented to participants consisted of 100 sentences, as can be seen in Table 1 .

All the sentences were organized in powerpoint (.ppt) files, and presented to learners one on each slide, on a Vaio PCG-V505ECP laptop computer in Brazil, and on a Dell Inspiron 1505 laptop computer in the United States. Learners were asked to read the content of the slides aloud. Participants were recorded individually. The Brazilian group was recorded in a soundproof booth in a special Laboratory, at the Journalism campus at UCPel. Recordings took place from May to July 2007. The NorthAmerican group was recorded in July 2007, in a silent room at the residence of one of the researchers, in the town of Amherst-Massachusetts. The sentences were recorded with the software Adobe Audition 2.0.

\section{Table 1}

Types and number of words presented in the carrier sentences

\begin{tabular}{l|l|l|l}
\hline Type of Word & $\begin{array}{l}\text { Number } \\
\text { of words }\end{array}$ & $\begin{array}{l}\text { Number of tokens } \\
\text { Each word }\end{array}$ & $\begin{array}{l}\text { Total Number } \\
\text { of tokens }\end{array}$ \\
\hline Target words & 12 & 5 & 60 \\
Distractor words & 8 & 5 & 40 \\
Total & 20 & & 100 \\
\hline
\end{tabular}


The words were segmented with Audacity 1.2.6 and later submitted to acoustic analysis with Praat - version 4.6.02 (Boersma \& Weenink, 2007). The following acoustic parameters were measured: 1 ) percentage of voicing in the obstruent closure; 2) duration of the vowel that precedes the final obstruent.

\section{Results and discussion}

In order to answer the research questions formulated at the beginning of this paper, statistical tests were run. As the participants repeated each one of the target words five times, the mean values were considered in the stats, for they tend to be more representative of the speech production of the speakers for every item. The few outliers ${ }^{5}$ and noisy productions were discarded from the data set with the use of the command Aggregate (SPSS, version 11.5).

Nonparametric tests were used due to the small sample size. For the two questions and hypotheses formulated, we used Mann-Whitney and Wilcoxon tests. This section is divided into two; the first one describes the results related to TD and the cue provided by the percentage of voicing in the closure, while the second one focuses on whether vowel duration can be seen as a significant cue for distinguishing voiced from voiceless final obstruents.

\subsection{Terminal Devoicing and voicing duration in the closure}

The first question addressed in this study concerned the issue of whether TD could be regarded as an interphonology process characterized by total neutralization of voicing. In case it is not, TD consists of partial neutralization of voicing, so our hypothesis is that Brazilian learners produce a significantly shorter percentage of voicing duration in the closure than American speakers of English do. The percentage was calculated by the ratio between the voicing duration in the closure and the total duration of the closure. ${ }^{6} \mathrm{~A}$ Mann-Whitney test (Table 2) was run with the results yielded by both groups. The median values refer to the percentage of voicing in the closure of final obstruents. 


\section{Table 2}

Mann-Whitney's test for comparison of the median percentages of voicing in the closure of final obstruents between the Brazilian and the American groups

\begin{tabular}{l|lll|lll|l}
\hline & $\begin{array}{l}\text { BRA } \\
\text { Minimum Median Maximum }\end{array}$ & & & \multicolumn{2}{l|}{$\begin{array}{l}\text { USA } \\
\text { Minimum Median Maximum }\end{array}$} & $\begin{array}{l}\text { Mann } \\
\text { Whitney's } \\
\text { U (p-value) }\end{array}$ \\
\hline CAB & $22.5 \%$ & $42.4 \%$ & $69.2 \%$ & $50.6 \%$ & $93.4 \%$ & $100.0 \%$ & $0.035^{*}$ \\
PAD & $9.4 \%$ & $49.8 \%$ & $96.2 \%$ & $96.2 \%$ & $100.0 \%$ & $100.0 \%$ & 0.024 \\
BAG & $41.3 \%$ & $56.0 \%$ & $79.6 \%$ & $36.0 \%$ & $86.4 \%$ & $100.0 \%$ & 0.497 \\
RAG & $10.3 \%$ & $41.6 \%$ & $76.1 \%$ & $66.6 \%$ & $69.1 \%$ & $100.0 \%$ & $0.048 *$ \\
BOB & $0.0 \%$ & $37.5 \%$ & $56.8 \%$ & $55.4 \%$ & $93.8 \%$ & $100.0 \%$ & $0.024^{*}$ \\
BAD & $12.0 \%$ & $33.8 \%$ & $92.2 \%$ & $86.4 \%$ & $100.0 \%$ & $100.0 \%$ & $0.024^{*}$ \\
\hline
\end{tabular}

* The difference between groups is statistically significant at 0.05 level.

From Table 2 we can see that, apart from the word bag, all words showed a significant difference between the two groups in terms of percentage of voicing in the closure. Therefore, our hypothesis was corroborated.

If we look at the median percentage of voicing in rag, we will notice that it is smaller than in the other stops for the American group. This is in accordance with the effects of place of articulation reported in the literature (Kingston, in press; Ladefoged \& Maddieson, 1996); that is, voicing decreases as the tongue moves backwards; thus, velar stops tend to get less duration of voicing than alveolars and bilabials do. However, the same pattern was not observed in the Brazilian group, as the voicing rates for bag and rag were higher than expected. In fact, except for these two words, the Brazilian group produced less than half of the percentage of voicing in the closure than North-Americans did in the other four ones. Even though we had expected final consonants to present a smaller rate of voicing than labials and coronals, the data produced by the Brazilian group presented a large amount of variability, 
which does not allow for generalizations about the relation between voicing and place of articulation.

Overall, the results displayed in Table 2 are in accordance with Yavas's (1997) findings, as they suggest that maintaining final voicing is harder for Brazilian learners than for American speakers. This may be an effect of the inexperience of Brazilian speakers with stops in coda position. As voiced plosives are always followed by a voiced segment in their L1, learners find it difficult to produce voicing in a stop whose release is not followed by another voiced segment. Thus, the rates of voicing in the closure might be related to the learners' proficiency level in the L2. In Zimmer and Alves' study, in which participants belonged to four different proficiency levels (most of them with lower levels of proficiency than the participants in this study), lower rates of voicing in the closure were found than the ones in Table 2 . This suggests that more proficient $\mathrm{L} 2$ learners might be more capable of maintaining final voicing than elementary students. Further studies considering a greater number of informants in different proficiency levels are, therefore, necessary.

\subsection{Terminal Devoicing and vowel duration}

The second question posed in the introduction of this paper addresses the role of the vowel preceding the final obstruent. The hypothesis based on this question is that vowel duration is a significant parameter distinguishing voiced from voiceless obstruents in the English spoken by Brazilian learners, similarly to what happens with native speakers of English. A Wilcoxon's Signed Ranks test between pairs was run to compare the length of vowels in voiced/voiceless pairs. The measures are presented in seconds in Table 3.

\section{Table 3}

Median, minimum and maximum vowel length values (in seconds) in the voiceless / voiced pairs of English words read by the Brazilian group 


\begin{tabular}{|c|c|c|c|c|c|c|c|c|}
\hline & Minimur & Median & Maximum & & Minimum & Median & Maxin & $\begin{array}{l}\text { ilcoxon's } \\
\text { p-value }\end{array}$ \\
\hline CAB & 0,184 & 0,216 & 0,274 & CAP & 0,168 & 0,211 & 0,249 & $0,039 *$ \\
\hline PAD & 0,211 & 0,224 & 0,299 & PAT & 0,173 & 0,213 & 0,275 & 0,078 \\
\hline BAG & 0,199 & 0,241 & 0,312 & BACK & 60,170 & 0,215 & 0,261 & $0,008^{*}$ \\
\hline RAG & 0,169 & 0,209 & 0,261 & RACK & 0,170 & 0,197 & 0,231 & 0,461 \\
\hline BOB & 0,177 & 0,201 & 0,266 & BOP & 0,148 & 0,196 & 0,247 & $0,016^{*}$ \\
\hline BAD & 0,185 & 0,227 & 0,279 & BAT & 0,184 & 0,208 & 0,265 & 0,250 \\
\hline
\end{tabular}

* The difference between pairs is statistically significant at 0.05 level.

Significant differences shown for only three of the six pairs in Table 3 do not fully corroborate our hypothesis. A significant difference in terms of vowel length is observed only in the minimal pairs cab/cap, bag/back, and bob/bop. As we will see in Table 4, although the length of vowels preceding voiced consonants seems to be close to native-like production, the length of the vowels preceding voiceless consonants produced by the Brazilian group is not as reduced as it should be. One of the possible reasons preventing learners from reducing the vowel length in words such as pat and cap might be the fact that they have not yet noticed that the vowel is shorter in such words.

It is also relevant to notice that the difference in vowel length varies according to the target pair. This may indicate that factors such as the learner's previous experience with the word, as well as the word's frequency are likely to play a role in the distinction concerning vowel length. Future investigations concerning factors such as word frequency as a variable determining vowel length are necessary.

As we consider the possibility that vowel length is a cue that might already be in use by our informants, it remains to be said whether the voiced/voiceless distinction produced by our learners differs considerably from the vowel length difference found among the American participants. In Table 4, we show the results of a MannWhitney test comparing the median vowels lengths between the two groups, for each one of the target words. 


\section{Table 4}

Mann-Whitney test comparing vowel durations between groups in all target items of the reading task

\begin{tabular}{l|lll|lll|l}
\hline & $\begin{array}{l}\text { BRA } \\
\text { Minimum Median Maximum }\end{array}$ & & \multicolumn{2}{l}{$\begin{array}{l}\text { USA } \\
\text { Minimum Median Maximum }\end{array}$} & $\begin{array}{l}\text { Mann } \\
\text { Whitney's U } \\
\text { (p-value) }\end{array}$ \\
\hline CAB & 0,184 & 0,216 & 0,274 & 0,212 & 0,220 & 0,227 & 1,000 \\
PAD & 0,211 & 0,224 & 0,299 & 0,235 & 0,240 & 0,308 & 0,279 \\
BAG & 0,199 & 0,241 & 0,312 & 0,291 & 0,294 & 0,351 & 0,133 \\
RAG & 0,169 & 0,209 & 0,261 & 0,233 & 0,241 & 0,267 & $0,048^{*}$ \\
BOB & 0,177 & 0,201 & 0,266 & 0,231 & 0,253 & 0,282 & 0,085 \\
BAD & 0,185 & 0,227 & 0,279 & 0,272 & 0,274 & 0,345 & 0,133 \\
CAP & 0,168 & 0,211 & 0,249 & 0,102 & 0,162 & 0,171 & $0,048^{*}$ \\
PAT & 0,173 & 0,213 & 0,275 & 0,112 & 0,181 & 0,188 & $0,048^{*}$ \\
BACK & 0,170 & 0,215 & 0,261 & 0,192 & 0,207 & 0,254 & 0,497 \\
RACK & 0,170 & 0,197 & 0,231 & 0,165 & 0,187 & 0,196 & 0,279 \\
BOP & 0,148 & 0,196 & 0,247 & 0,167 & 0,169 & 0,228 & 0,497 \\
BAT & 0,184 & 0,208 & 0,265 & 0,175 & 0,222 & 0,242 & 1,000 \\
\hline
\end{tabular}

* The difference between pairs is statistically significant at 0.05 level.

As we look at the production of the words ending in a voiced segment (cab, pad, bag, bob, bag, rag), we see that the median length is always shorter among the Brazilian informants. This difference, however, was significant only in the case of rag, probably due to the small sample size. In words ending in voiceless plosives, the vowels produced by the learners yielded a greater median length than those produced by the American participants. In a dynamic approach to SLA, the difference between producing an L1 and an L2, as Silva (2008) points out, seems to lie in the duration of the acoustic events. When we argue in favor of a dynamic approach, we want to highlight the interactivity between learner's motor-perceptual abilities and procedural memories, which explains what learners are in fact doing when they exhibit productions such as the ones we have just described. 
In order to acquire the vowel length contrast, learners have to listen for this cue. The data suggest that learners may be simply engaging in phonetic-phonological transfer, as vowel length is not a cue distinguishing between voiced and voiceless syllable-final sounds in Brazilian Portuguese. Consequently, Brazilian learners do not seem to be distinguishing vowel length in English, and their productions tend to be closer in length to the vowels preceding voiced consonants in English. Thus, acquiring the vowel length distinction means starting to rely less on L1entrenched system and focusing more on the L2 auditory cue.

\section{Final remarks}

Having discussed our findings, and bearing in mind that the present study had a small number of participants, it is clear that looking at Terminal Devoicing among Brazilian learners of English as an interlanguage rule, as it was formulated by Eckman (1987), does not conform to a dynamic approach to SLA, since we did not observe the loss of the sonorant feature or the neutralization of the voicing contrast in the Brazilian participants' production. Rather, we interpret our data as evidence against a view of interphonology based on the loss of segments or features characterized by binary and dichotomous oppositions, such as the one between voiced and voiceless features. In this study we used two acoustic correlates to stand for a measure of voicing: the percentage of duration of voicing in the closure and duration of the preceding vowel.

Although Brazilian learners do not maintain voicing in the closure for as long as the American speakers do, their production of stops cannot be regarded as totally voiceless. Thus, as far as closure voicing is concerned, informants were able to produce final $/ \mathrm{p} /, / \mathrm{t} /, / \mathrm{k} /$ and $/ \mathrm{b} /, / \mathrm{d} /, / \mathrm{g} /$ differently, as the latter segments are produced with at least some voicing. In other words, even though maintaining voicing in the closure can be regarded as a difficult task for Brazilian learners, final consonants cannot be regarded as fully devoiced in Interlanguage Phonology, as had been previously claimed in the binary categorization 
by Major (1987). Although further studies are necessary in order to show that Brazilian English /p/,/t/, / / / and /b/,/d/, /g/ in final position can be perceived as different segments, we believe that the rates of voicing shown in Figure 1, for instance, are enough to distinguish final voiceless from final voiced consonants.

Concerning the vowel length cue, the duration of vowels preceding final stops does not seem to be working as a cue in the production of our informants. These results can be looked at in terms of the dynamic characteristic of L1-L2 transfer, generating a great deal of interactivity between long-term memories (linguistic and non-linguistic) and shortterm memory, which seems to be under way when the L1 entrenched phonetic-phonological representations may bias $\mathrm{L} 2$ speech production. In other words, producing the vowel-length distinction in English among Brazilian learners implies overcoming the influence played by the L1 phonetic-phonological pattern.

In sum, this study presents two main important findings: 1) the Brazilian participants produce a percentage of voicing in the closure that does not show a neutralization of contrast between voiceless and voiced stops; 2) the Brazilian participants are producing vowels preceding voiced obstruents with a longer duration than the vowels preceding the voiceless stops; however, the duration of vowels preceding voiceless stops is still longer in the Brazilian production than in the American production.

After examination of the findings concerning the two acoustic correlates of voicing measured in this study, which are both related to the time cue in the acoustic components, we have demonstrated the importance of gestures, as opposed to contrasting phonemes, in interlanguage phonology. A gestural view of L2 production is fundamental to account for the dynamics of second language phonological acquisition. We cite the words of Silva:

The consequence of assuming a dynamic view of L2 phonological acquisition is that learners have to be taught 
how to relate the articulatory strategies they already produce following the timing of these articulatory strategies in L2. It's not the case, then, to teach the students what they already know and what they are already able to produce. This perspective requires the teacher to see his student in a different way, i.e., not as one who does not know how to produce sounds or sequences of sounds, but as one who is capable of producing a number of articulatory gestures that are organized differently from language to language. The students need then to learn how to coordinate the gestures as it is in the L2 they are acquiring. (Silva, 2008, p. 11)

Considering our findings in the light of the lines above, we hope to have been able to show that the dynamic view of SLA advocated by Silva (2008) is consonant with the approach advocated here, which takes language as a phenomenon that takes place in time and which is the product of a highly interactive memory system, enhancing the role of L1 experience and transfer in the interactions between the native and the second language phonetic-phonological system.

\section{Notes}

1. We do not adopt the distinction between the terms "foreign" and "second language/L2", because we understand that adopting this distinction implies the acceptance of the Krashean distinction between learning and acquisition, with which we do not agree either.

2. In line with Silva (2008), we call "classic approaches to interphonology" those models that are grounded on generative phonology, whose theories "are all theories of extrinsic timing" (Silva, 2008, p. 2), and reflect a cartesian look at the study of speech production and perception, seen as categorical and mostly informed by the notion of markedness and the processing of binary features. Hence, we view the terms "classic approaches to interphonology" and "generative phonology" as synonyms, and we contrast them to more recent and innovative ones, the so-called "dynamic models of speech production". Moreover, the term "symbolic" is contrasted here to the connectionist paradigm of cognition, which seems to be in accordance with a dynamic view of language acquisition. 
3. We use the term "grapho-phonic-phonological knowledge" to refer to the orthography-phonology relationship configured between the spelling, the phonological representation, and the phones produced when reading aloud. The phrase "phonetic-phonological" expresses the continuum between the physical phone and the abstract phoneme (Albano, 2001, 2007), which is explained in detail in Zimmer \& Alves (2006).

4. Terminal Devoicing may also be studied as a case of grapho-phonic-phonological transfer, but the data collected here cannot account for it.

5. A few tokens were considered outliers when participants changed the quality of the target vowel (e.g., the vowel in bad produced as [I]).

6. We would like to point out that the percentages displayed in the Tables in this paper do not refer to proportions calculated for 8 or 3 participants; rather, they refer to the mean ratio between two acoustic measures repeated five times for each participant.

\section{References}

Albano, E. C. (1999). Criatividade e gradiência num léxico sem derivações. In: L. Cabral L. G \& J. Morais (Eds). Investigando a linguagem. Florianópolis: Mulheres, pp. 35-54.

Albano, E. C. (2001). O gesto e suas bordas: esboço de fonologia acústico-articulatória do português brasileiro. Campinas: Mercado de Letras, ALB, Fapesp.

Albano, E. C. (2007). Representações dinâmicas e distribuídas: indícios do português brasileiro adulto e infantil. Letras de Hoje, 42 (1), 131-150 .

Boersma, P. \& Weenink, D (2007). Praat: doing phonetics by computer.

Celce-Murcia, M., Brinton, D. \& Goodwin, J. (1996). Teaching Pronunciation: A Reference for Teachers of English to Speakers of Other Languages. New York: Cambridge University Press.

Eckman, F. R. (1987). Markedness and the contrastive analysis hypothesis. In G. Ioup \& S. H. Weinberger (Eds.), Steven H. Interlanguage phonology: The acquisition of a second language sound system (pp. 55-69). Cambridge, MA: Newbury House. 
Eckman, F. R. (1996). On evaluating arguments for special nativism in second language acquisition theory. Second Language Research, 12, 398-419.

Eckman, F.R. (2004). From phonemic differences to constraint rankings: research on second language phonology. Studies in Second Language Acquisition, 26, 513549 .

Ellis, N. (1999). Emergentism, connectionism and language learning. Language Learning, 48(4), 631-664.

Ellis, N. (2005). At the interface: dynamic interactions of explicit and implicit language knowledge. Studies on Second Language Acquisition, 27, 305-352.

Elman, J., Bates, E., Johnson, M., Karmiloff-Smith, A., Parisi, A., \& Plunkett, K. (1996). Rethinking innateness: a connectionist perspective on development. Cambridge, M.A.: MIT.

Ernestus, M. \& Baayen, H. (2006). The functionality of incomplete neutralization in Dutch: the case of past-tense formation. In: GOLDSTEIN, Louis; WHALEN, D. H.; BEST, Catherine D. (ed). Laboratory Phonology 8. Berlin: De Gruyter, 29-51.

Escudero, P. (2007). Explaining the interrelation between auditory and orthographic cues in L2 sound perception and word recognition. Fifth International Symposium on the Acquistion of Second Language Speech: Conference Program and Abstract Book, p.14. Florianópolis, Brazil.

Flege, J. E; McCutcheon, M; Smith, S. (1987). The development of skills in producing word-final stops Journal of Acoustic Society of America, 82 (2), 433-447,

Gasser, M. (1990). Connectionism and universals in second language acquisition. Studies in Second Language Acquisition, 12, 170-199.

Haspelmath, M. (2006). Against markedness (and what to replace it with). Journal of Linguistics, 42, 25-70.

Joanisse, M. F. (2000). Connectionist Phonology. Unpublished Ph.D. Dissertation, University of Southern California.

Kingston, J. Introduction to phonetic theory. Manuscript copy. 
Krashen, S. (1982). Second language acquisition and second language learning. Oxford: Pergamon.

Ladefoged, P. (1993). A course in Phonetics. $3^{\text {rd }}$ edition. Harcourt.

Lauefeur, C. (1992). Patterns of voicing-conditioned vowel duration in French and English. Journal of Phonetics, 20, 411-440.

Lisker, L. (1986). "Voicing” in English: A catalogue of acoustic features signaling /b/ versus /p/ in trochees. Language and Speech, 29, 3-11.

MacWhinney, B. (2001). The competition model: The input, the context, and the brain. In: ROBINSONS, Peter (ed). Cognition and second language instruction (pp. 6990). Cambridge University Press.

MacWhinney, B. (2007). Emergent fossilization. In Z. Han \& T. Odlin (Eds.). Perspectives on fossilization (pp. 134-156). Clevedon, UK: Multilingual Matters.

Major, R. (1987). A model for interlanguage phonology. In G. Ioup \& S. H. Weinberger (Eds.), Interlanguage phonology: The acquisition of a second language sound system (pp. 101-124). Cambridge, MA: Newbury House.

Piroth, H. G. \& Janker, P (2004). Speaker-dependent differences in voicing and devoicing of German obstruents. Journal of Phonetics, 32, 81-109.

Seidenberg, M. \& Zevin, J. (2006). Connectionist models in developmental cognitive neuroscience: Critical periods and the paradox of success. In Y. Munakata \& M. Johnson (Eds.), Attention \& Performance XXI: Processes of Change in Brain and Cognitive Development. Oxford: Oxford University Press.

Silva, A. H. P. (2008). Towards a dynamic view on L2 phonological acquisition. In Rauber, A.S., Watkins, A. M. A., \& Baptista, B. O. (Eds.), New Sounds 2007: Proceedings of the Fifth International Symposium on Second Language Speech (pp. 446-458). Florianópolis, Brazil, Universidade Federal de Santa Catarina.

Silveira, R. (2004). The influence of pronunciation instruction on the perception and the production of English word-final consonants. Unpublished Doctoral Dissertation, Florianópolis (Brazil): Universidade Federal de Santa Catarina.

Smith, C. L. (1997). The devoicing of /z/ in American English: effects of local and prosodic context. Journal of Phonetics, 25, 471-500. 
Zimmer, M. C. (2004). A transferência do conhecimento fonético-fonológico do português brasileiro (L1) para o inglês (L2) na recodificação leitora: uma abordagem conexionista. Porto Alegre, Brazil. Universidade Pontificia do Rio Grande do Sul.

Zimmer, M. C. \& Alves, U. K. (2007). A dessonorização terminal na aprendizagem da L2: Evidências do continuum fonética-fonologia. Letras de Hoje, PUCRS, 42 (3), 59-76.

Zimmer, M. C., Silveira, R., Alves, U. K. (in press). Pronunciation instruction for Brazilians: Bringing theory and practice together. Cambridge Scholars Publishing.

Yavas, M. (1997). The effects of vowel height and place of articulatio $n$ in interlanguage final stop devoicing. International Review of Applied Linguistics, 35,115-125. 